\title{
COVID-19: A Dermatologist's Experience From the US Epicenter
}

\author{
Yasaman Mansouri, MD, MRCP
}

\section{PRACTICE POINTS}

- Coronavirus disease 2019 (COVID-19) can spread quickly, creating chaos in the health care system and leading to critical supply shortages within a short amount of time.

- Social distancing, quarantine, and isolation appear to be powerful tools in reducing the spread of COVID-19.

7 he 1918 H1N1 influenza pandemic was the most severe pandemic in recent history. Fifty to 100 million individuals died worldwide, with approximately 675,000 deaths in the United States. ${ }^{1-3}$ The fatality rate was approximately $2 \%$ and was highest during the second and third waves of the disease. ${ }^{4}$ At that time, there were no diagnostic tests for influenza infection, influenza vaccines, antiviral drugs, antibiotics to treat secondary bacterial infections, or mechanical ventilation. Some cities decided to close schools, limit public gatherings, selfisolate, and issue quarantine orders; the federal government took no central role.

The 1918 influenza pandemic seems far away in history, but my mother often tells me stories about her own grandmother who disliked shaking anyone's hands and would worry when people coughed or sneezed around her. It sounded like she was overreacting. Now, we can better relate to her concerns. Life has changed dramatically.

In mid-February 2020, news spread that the coronavirus disease 2019 (COVID-19) had spread from Wuhan,
China, to a number of countries in Asia and the Middle East. I was following the news with great sadness for those affected countries, especially for Iran, my country of origin, which had become an epicenter of COVID-19. We were not worried for ourselves in the United States. These infections seemed far away. However, once Italy became the new epicenter of COVID-19 with alarmingly high death rates, I grasped the inevitable reality: The novel coronavirus would not spare the United States and would not spare New York.

Then the virus arrived in New York City. On March 10, 2020, our hospital recommended using teledermatology instead of in-person visits in an attempt to keep patients safe in their own homes. Cases of COVID-19 were escalating, hospitals were filling up, health care workers were falling ill, and there was a shortage of health care staff and personal protective equipment (PPE). Dermatologists at various hospitals were asked to retrain to help care for COVID-19 patients.

On March 13, flights from Europe to the United States were suspended. A statewide stay-at-home order subsequently went into effect on March 22. It felt surreal. From March 23 on, various specialty physicians and nurses in our hospital volunteered to work as frontline staff in the newly prepared annex where patients with possible COVID-19 would arrive. My dermatology co-residents and I started working as frontline physicians. Everything we had heard from the countries affected first had become our reality. Our hospital, part of the largest public health care system in the nation, became a dedicated COVID-19 treatment center.

Large numbers of scared patients with symptoms of COVID-19 flooded the annex. We sent the majority of

Dr. Mansouri is from the Department of Dermatology, NYC Health + Hospitals/Metropolitan, New York

The author reports no conflict of interest.

Correspondence: Yasaman Mansouri, MD, MRCP, Department of Dermatology, Metropolitan Hospital, 1901 First Ave, New York, NY 10029 (yamansouri@gmail.com).

doi:10.12788/cutis.0029 
them home, unable to offer them even a diagnostic test, and advised them to stay isolated. We only had the capacity to test those who required hospital admission.

It broke my heart even more when my colleagues became patients. We often felt helpless, not being able to help every patient and not being able to help our infected colleagues.

Elective surgeries were suspended. Inpatient beds, including specialized intensive care unit beds, rapidly filled up with COVID-19 patients. To help with the surge of patients, our hospital added medical and intensive care unit beds. The hospital became surreal, the corridors eerily empty and silent while every bed was filled, and health care workers were rushing around the inpatient units.

Life quickly became filled with fears-worries about how sick the patients would be, how much we would be able to help them, whether we would have enough PPE, who among our friends or family might be infected next, and whether we might ourselves be next. As PPE became scarce, I desperately searched for some form of protective equipment. I hunted for protective masks, face shields, eye protection, and gowns. We had to reuse disposable N95 masks and face shields multiple times and disinfect them as best we could. Our attendings ordered any protective gear they could find for us. Nearly everything was sold out; the very few items remaining would not for arrive for months. I could have never imagined that I would be afraid of going to work, of not having the appropriate protective gear, and that any day might be my last because of my profession.

New York City had become the epicenter of COVID-19. The city, the country, and the world were in chaos. Hospitals were overflowing, and makeshift morgues were appearing outside of hospitals. Those who could fled the city. Despite warnings from experts, we were not prepared. The number of deaths was climbing rapidly. There was no clarity on who could be tested or how to get it done. It felt like a nightmare.

Social distancing was in place, nonessential businesses were shut down, street vendors disappeared, and people were advised to wear face coverings. People were afraid of each other, afraid of getting too close and catching the virus. New York City—The City That Never Sleeps—went into deep sleep. Every day brought ever greater numbers of infected patients and more deaths.

Every day at 7:00 PM, people in New York City started clapping from their windows to salute health care workers, bringing tears to my eyes-tears for the gratitude of people mixed with tears of fear for my life and the lives of my patients and colleagues. I made arrangements for the event of falling ill, including a list of names and contact details of my family and close friends so they could be reached in case I ended up in intensive care or died.

After around 2 months of lockdown, New York City passed its peak, and the epicenter moved on. The current death toll (ie, confirmed deaths due to COVID-19) in New York stands at 18,836, while the reported death toll in the United States is 143,868 , according to the Centers for Disease Control and Prevention. New York City has started a phased reopening to a new normal. Elective care has resumed, and people are leaving their homes again, eager to bring some sense of normalcy back into their lives.

I fear for those who will contract the virus in the next wave. I wonder what we will have learned.

Acknowledgment-The author wishes to thank Steven R. Feldman, MD, PhD (Winston-Salem, North Carolina), for his friendship and invaluable assistance with the conception and editing of this manuscript.

\section{REFERENCES}

1. Taubenberger JK. The origin and virulence of the 1918 "Spanish" influenza virus. Proc Am Philos Soc. 2006;150:86-112.

2. Morens DM, Taubenberger JK. The mother of all pandemics is 100 years old (and going strong)! Am J Public Health. 2018;108:1449-1454.

3. Johnson NPAS, Mueller J. Updating the accounts: global mortality of the 1918-1920 "Spanish" influenza pandemic. Bull Hist Med. 2002;76:105-115.

4. Morens DM, Fauci AS. The 1918 influenza pandemic: insights for the 21st century. J Infect Dis. 2007;195:1018-1028. 